\title{
On the Confinement Effect During Catalytic Reaction Over Al-MCM-41
}

\author{
Wen-Hua Chen · Shing-Jong Huang • Qi Zhao · \\ Hong-Ping Lin · Chung-Yuan Mou · Shang-Bin Liu
}

Published online: 23 December 2008

(C) Springer Science+Business Media, LLC 2008

\begin{abstract}
A comprehensive study has been made on the cracking abilities of mesoporous aluminosillicate MCM-41 materials with different Si/Al ratios $(15-\infty)$ and pore diameters (1.6-3.0 $\mathrm{nm}$ ) by using 1,3,5-triisopropylbenzene $(1,3,5$-TiPB $)$ cracking as the test reaction. The roles of $\mathrm{Al}$ content and pore diameter on the catalytic features of the samples were evaluated by the conversion of 1,3,5-TiPB, coke content and deactivation parameters. It is found that the catalytic activity is mainly controlled by adsorptive properties towards the reactant and the dispersion of acid sites. In terms of their catalytic performances, cracking reaction over aluminosilicate mesoporous materials is more
\end{abstract}

W.-H. Chen · Q. Zhao · H.-P. Lin · S.-B. Liu $(\bowtie)$

Institute of Atomic and Molecular Sciences, Academia Sinica, P.O. Box 23-166, Taipei 106, Taiwan, ROC

e-mail: sbliu@sinica.edu.tw

Present Address:

W.-H. Chen

Environment and Energy Technology Center, Institute

of Nuclear Energy Research, Taoyuan 325, Taiwan, ROC

S.-J. Huang · C.-Y. Mou $(\square)$

Department of Chemistry and Center for Condensed Matter Research, National Taiwan University, Taipei 106, Taiwan, ROC

e-mail: cymou@ntu.edu.tw

Present Address:

Q. Zhao

Department of Chemistry, Tulane University,

New Orleans, LA 70118, USA

Present Address:

H.-P. Lin

Department of Chemistry, National Cheng Kung University,

Tainan 700, Taiwan, ROC favorable for catalysts with smaller pore size and higher $\mathrm{Al}$ concentration. Moreover, coking is found responsible for catalyst deactivation during 1,3,5-TiPB cracking reaction over Al-MCM-41.

Keywords Confinement effect · Cracking · Mesoporous Al-MCM-41 · Si/Al ratio · Pore size · Coking

\section{Introduction}

Mesoporous silica molecular sieve [1, 2], such as MCM41, whose structure consists of uniform channels with tunable pore size (typically from 1.5 to $10.0 \mathrm{~nm}$ ) [3, 4], and controllable morphology $[5,6]$, are known to possess high surface area (ca. $1,000 \mathrm{~m}^{2} / \mathrm{g}$ ), high hydrocarbon sorption capacities $(>0.7 \mathrm{~mL} / \mathrm{g})$, and high thermal and hydrothermal stabilities. Furthermore, their pore surfaces can be easily functionalized for tailored purposes [7, 8]. As such, these unique properties render their applications in a wide range of areas, for example, as in sorption/separation processes [9], electronic/optical materials [10], and catalytic reactions [11].

In many of these applications, the pores are used to produce some nano-scale confinement effect. It is wellknown that many physicochemical properties of fluids are altered strongly when they are confined in nanopores [12]. For examples, notable effects in adsorption energies [13], phase equilibrium [14], and diffusion [15, 16] were commonly observed for confined fluids. An obvious controlling factor would be the size of the nanopores of the host adsorbent; a smaller pore size usually give rise to a higher heat of adsorption [17] and more hindered transport [15] of the guest adsorbate. Since the pore size of mesoporous 
aluminosilicates can be controlled in a wide range to high uniformity, it has been employed to study the size effects of various physicochemical phenomena.

For chemical reactions in confined nanospace, one could further expect many interesting pore size effects. However, its interpretation is usually difficult. This is due to the complicated interplays of equilibrium shift, surface effects on activated complexes, and diffusion effects of the catalysis system in confined space. An experimental investigation of the role of each possible effect is challenging, since experimental measurements reflect integration over multiple effects. At present, we have only limited ability to disentangle these factors in a given confined reaction system $[18,19]$. As such, carefully designed experiments focusing on a systematic study of the pore size effect for catalytic reactions in mesoporous materials would be highly desirable.

Developments in the synthesis of mesoporous silica provide such an opportunity in making nano-reactors of controllable sizes available. Konishi et al. [20] investigated a liquid-phase photoreaction in mesoporous silica and proposed that the pore size effect is due to inhibition of the drift-away of the radical pairs produced. Wei et al. [21] found a strong effect of pore size on the catalytic activities of vanadium substituted MCM-41. Jaenicke and co-workers [22] studied alkylation of benzene catalyzed by $\mathrm{AlCl}_{3}$ immobilized on MCM-41 and found higher selectivity of monoalkylated (versus dialkyl) benzene in smaller pores. Iwamoto et al. [23] observed an optimum pore size (at $1.9 \mathrm{~nm}$ ) for cyclohexanone acetalization catalyzed by mesoporous aluminosilicates. However, in these earlier works there was lack of complete control of materials parameters such as surface acidity, pore size, or pre-treatment conditions. Furthermore, the interaction between pore surface and reactants were not characterized. Thus, the cause of the pore size effect could only be speculated.

More recently, systematic controls of catalysts and activity/interaction correlations have been carried out to understand the confinement effect. Pariente et al. [24], in studying the isomerization of 1-hexene on MCM-41 materials, observed a correlation between adsorption heat and activity both which are pore-size dependent. Yang et al. [25] studied pore-size effect of methanol oxidation on V-MCM-41. They found, through temperature-programmed reduction of V-MCM-41 catalysts, that reduction stability was influenced by the radius of curvature. In both works, a volcano curve was found in which catalytic activity increases with decreasing pore diameter to a maximum and then decreases. Such "volcano curve" has also been found in other confined reactions, such as cyclohexanone acetalization on mesoporous aluminosilicates [23], nitroaldol condensation catalyzed by aminefunctionalized mesoporous silica of uniform morphology
[26], and Fischer-Tropsch synthesis catalyzed by Co-supported mesoporous silica [27]. In a recent highlight, Goettman and Sanchez [28] called for more detailed studies to understand confinement effect of catalytic activity using mesoporous materials.

In this paper, a comprehensive study on 1,3,5-triisopropylbenzene (1,3,5-TiPB) cracking reaction over Al-MCM-41 is reported. This system is chosen because the size effects on the adsorption of hydrocarbons into the nanochannels have been carefully studied by calorimetry [29-31]. Since the first step in catalytic cracking is the adsorption of the reactant into the acidic porous materials, one would have a good basis to examine the pore size effect on catalytic activity.

It is well-known that the activity of a solid acid catalyst is mainly dictated by its acidic and molecular transport properties. The former depends strongly on the concentration and distribution of framework acidic species, whereas the latter may be manipulated by the structural porosity of the catalyst. Acidic mesoporous molecular sieves, such as Al-MCM-41, are good candidates as catalysts or supports for catalytic reactions. In order to achieve high activity and selectivity, it is important to control both the pore size and the acidity. A great deal of interests has been developed in utilizing Al-MCM-41 to catalyze large organic molecules [32-34]. In this context, Al-MCM-41 materials, being less acidic compared to most microporous zeolites and can be produced in a wide range of $\mathrm{Al}$ concentrations, pore sizes and morphologies under tailored synthesis conditions are most suitable for catalytic cracking of bulky hydrocarbons by which only weak acidity is required [35-38]. In a previous study, we investigated the catalytic performances of a series of Al-MCM-41 samples with particulate and hierarchical morphologies during 1,3,5-triisopropylbenzene (1,3,5-TiPB) cracking reaction [15]. It was found that, samples with inter-channel connections [39-41] showed superior catalytic activities and tolerances for coking and deactivation due to higher diffusivity caused by inter-channel connections, which facilitate transport of hydrocarbons.

In this paper, we focus on the cracking capability over Al-MCM-41 catalysts with carefully controlled pore sizes and aluminum contents. Specifically, the effects of $\mathrm{Al}$ content and pore size on catalytic performance of AlMCM-41 during 1,3,5-TiPB cracking reaction are investigated. Through detailed correlations of reaction activities with pore sizes and alumina contents, the "pure" confinement effect can be isolated and studied. We correlate the confinement effect with the variation of temperature of desorption to understand the pore-size trend in catalytic activity. In addition, we also investigate catalyst de-activation due to coking, which is important in practical applications. 


\section{Experimental}

\subsection{Materials}

The silica source is sodium silicate (27\% $\mathrm{SiO} 2,14 \%$ $\mathrm{NaOH}$ ) from Aldrich, and the source of aluminum is sodium aluminate $\left(\mathrm{NaAlO}_{2}\right)$ from Riedel-de Haën. The templating agents are alkyltrimethylammonium halides $\left[\mathrm{C}_{n} \mathrm{H}_{2 n}+1\left(\mathrm{CH}_{3}\right)_{3} \mathrm{NBr} ; n=10-18\right.$ (even number)] from Acrôs. Powdered Al-MCM-41 molecular sieves with varied $\mathrm{Si} / \mathrm{Al}$ ratios $(15-\infty)$ and pore sizes $(1.6-3.0 \mathrm{~nm})$ were synthesized by the "delayed neutralization" procedure [42-44] using sodium silicate, sodium aluminate and $\mathrm{C}_{n}$ TMAB $(n=10,12,14,16$, and 18) as the source materials for $\mathrm{Si}, \mathrm{Al}$ and quaternary ammonium surfactants, respectively. To repare pure-silica MCM-41 materials, sodium silicate was added to a clear aqueous solution of the surfactant under stirring and a gel mixture was formed. After stirring for about $10 \mathrm{~min}$ at room temperature, a proper amount of $1.10 \mathrm{M}$ sulfuric acid was added into the gel mixture with a pipette. This step takes up to $30 \mathrm{~min}$. The $\mathrm{pH}$ value of the final mixture was adjusted to about 10 . Generally, the molar composition of the resultant gel to prepare the well-ordered MCM-41 materials is: 1.0 $\mathrm{C}_{n}$ TMABr: $2.10 \quad \mathrm{SiO}_{2}$ : (0-0.21) $\mathrm{NaAlO}_{2}$ : (1.63-1.20) $\mathrm{NaOH}$ : (0.67-0.40) $\mathrm{H}_{2} \mathrm{SO}_{4}$ : (50-500) $\mathrm{H}_{2} \mathrm{O}$. All as-synthesized samples were first calcined in air at $833 \mathrm{~K}$ for $6 \mathrm{~h}$ to remove organic templates. ICP-AES elemental analysis of the calcined samples confirmed that the quoted $\mathrm{Si} / \mathrm{Al}$ ratios are accurate to within \pm 3 . Additional experiment by ${ }^{27} \mathrm{Al}$ MAS NMR also verified that, except for sample with lowest $\mathrm{Si} / \mathrm{Al}$ of 15 in which trace amount of octahedral $\mathrm{Al}$ species were present, nearly all of the Al in the Al-MCM41 samples examined are tetrahedral coordinated. The structures of all MCM-41 samples were confirmed by powder X-ray diffraction (XRD). Scanning/transmission electron microscopy (SEM/TEM) revealed that all samples possess the conventional particulate morphology and similar averaged particle size of ca. $0.3 \mu \mathrm{m}$. The average pore diameters and surface areas of the samples were calculated using the BJH method and the BET procedure based on the desorption curve of the $\mathrm{N}_{2}$ adsorption-desorption isotherms obtained at $77 \mathrm{~K}$, respectively (Table 1 ).

\subsection{Cracking Reaction}

1,3,5-TiPB cracking was used as test reaction throughout the study. Reagent 1,3,5-TiPB (A.R. grade, ACROS) was purified by molecular sieve $4 \mathrm{~A}$ before use. All reactions were conducted in a continuous flow, fixed-bed reactor under the following conditions: temperature $\left(T_{\mathrm{r}}\right)=573 \mathrm{~K}$; weight hourly space velocity $(\mathrm{WHSV})=15.25 \mathrm{~h}^{-1}$; pressure $(P)=1$ atm; carrier gas: $\mathrm{N}_{2}$; carrier gas to feed ratio
$\left(\mathrm{N}_{2} /\right.$ feed $)=2.0 \mathrm{~mol} / \mathrm{mol}$, time-on-stream $(\mathrm{TOS})=0-6 \mathrm{~h}$. Prior to each run, ca. $1 \mathrm{~g}$ of palletized Al-MCM-41 (10-20 mesh) was packed into the reactor, then the catalyst was first activated in air at $723 \mathrm{~K}$ for $8 \mathrm{~h}$ before the reactor was eventually cooled (under $\mathrm{N}_{2}$ stream) down to the desired reaction temperature. The compositions of the reactor effluents were analyzed by gas chromatography (Shimadzu GC-9A) using a packed column (5\% SP-1200 + $1.75 \%$ Bentone 34 on 100/120 Supelcoport, $6 \mathrm{ft}$ ). All products were identified using internal standard method. Upon completion of the experiment, the catalyst was purged with $\mathrm{N}_{2}$ at $T_{\mathrm{r}}$ for $0.5 \mathrm{~h}$, then, the reactor temperature was reduced to $473 \mathrm{~K}$ and maintained in the same condition for over $6 \mathrm{~h}$ to ensure complete removal of reactant/product residues in the catalyst before it was finally cooled down to room temperature (298 K).

The amount of carbonaceous residues retained in each fouled sample was determined by thermogravimetric analysis (TGA; Netzsch TG209). In a typically experiment, ca. $10 \mathrm{mg}$ of catalyst was heated to $1,173 \mathrm{~K}$ at a rate of $10 \mathrm{~K} / \mathrm{min}$ under dried air. The coke content was determined from the weight loss between the temperature ranges of $573-973 \mathrm{~K}$.

\section{Results and Discussion}

\subsection{Catalytic Performance During 1,3,5-TiPB Cracking Reaction Over Al-Mcm-41}

The catalytic activities of various Al-MCM-41 samples were assessed by the conversion of 1,3,5-TiPB, which was catalyzed to produce mainly mono- and di-substituted isopropylbenzenes. In general, the yields of major products were all found to obey the order: $m$-DiPB $\gg$ cumene $>$ $p$-DiPB $>o$-DiPB $>$ propene $\gg$ benzene. Only trace amount of benzene yield was observed at $T_{\mathrm{r}}=573 \mathrm{~K}$. This is reasonable since it in the order of sequential de-alkylation and transakylation reaction.

Unlike Al-containing MCM-41 molecular sieves, which render formation of acid sites requisite for catalytic reactions, siliceous MCM-41 materials are expected to exhibit little catalytic activity due to their neutrally charged structural framework. To investigate the effect of Al content on catalytic performance of Al-MCM-41 during 1,3,5TiPB cracking reaction, a series of samples with varied $\mathrm{Si} /$ Al ratios (15-370) and pore diameters were prepared (Table 1). Figure 1a shows the variations of 1,3,5-TiPB conversions with time-on-stream (TOS) during cracking reactions over various MCM-41 samples with an averaged pore size of ca. $2.6 \mathrm{~nm}$. It can be seen that, with the exception of sample SMCM-C16 (i.e. pure siliceous MCM41 with $\mathrm{Si} / \mathrm{Al}=\infty$ ), which revealed the expected null 
Table 1 Characteristics and catalytic properties of various MCM-41 samples

\begin{tabular}{|c|c|c|c|c|c|c|c|c|c|}
\hline \multicolumn{5}{|l|}{ Fresh catalyst } & \multicolumn{5}{|l|}{ Spent catalyst } \\
\hline \multirow[t]{2}{*}{ Sample } & \multirow[t]{2}{*}{$\mathrm{Si} / \mathrm{Al}$} & \multirow{2}{*}{$\begin{array}{l}\text { Pore diameter } \\
(\mathrm{nm})^{\mathrm{a}}\end{array}$} & \multirow{2}{*}{$\begin{array}{l}\text { Pore volume } \\
(\mathrm{mL} / \mathrm{g})^{\mathrm{b}}\end{array}$} & \multirow{2}{*}{$\begin{array}{l}\text { Surface area } \\
\left(\mathrm{m}^{2} / \mathrm{g}\right)^{\mathrm{b}}\end{array}$} & \multirow{2}{*}{$\begin{array}{l}\text { Coke content } \\
(\mathrm{wt} \%)^{\mathrm{c}}\end{array}$} & \multicolumn{4}{|c|}{ Deactivation parameter ${ }^{\mathrm{d}, \mathrm{e}}$} \\
\hline & & & & & & $X_{o}$ & $\kappa$ & $\alpha$ & $X_{o}+\kappa^{\mathrm{f}}$ \\
\hline MCM-C16/15 & 15 & 2.62 & 0.98 & 1015 & 4.5 & 29.2 & 38.3 & 0.81 & 67.5 \\
\hline MCM-C16/20 & 20 & 2.68 & 0.94 & 927 & 4.1 & 23.1 & 33.0 & 0.51 & 56.1 \\
\hline MCM-C16/37 & 37 & 2.54 & 1.15 & 1064 & 4.3 & 25.5 & 23.6 & 0.59 & 53.3 \\
\hline MCM-C16/60 & 60 & 2.58 & 1.02 & 1135 & 4.3 & 22.3 & 19.8 & 0.87 & 42.1 \\
\hline MCM-C16/120 & 120 & 2.61 & 0.98 & 1093 & 3.7 & 17.4 & 20.4 & 0.79 & 37.8 \\
\hline MCM-C16/177 & 177 & 2.56 & 1.05 & 983 & 3.1 & 7.8 & 29.3 & 0.77 & 37.1 \\
\hline MCM-C16/370 & 370 & 2.58 & 0.98 & 1027 & 2.6 & 7.7 & 27.8 & 0.87 & 35.5 \\
\hline SMCM-C16 & $\infty$ & 2.66 & 0.94 & 1074 & - & - & - & - & - \\
\hline MCM-C10/37 & 37 & 1.57 & 0.81 & 1191 & 9.6 & 12.9 & 80.7 & 0.75 & 93.6 \\
\hline MCM-C12/37 & 37 & 1.80 & 0.96 & 1291 & 4.4 & 40.0 & 50.3 & 0.50 & 90.3 \\
\hline MCM-C14/37 & 37 & 2.18 & 0.96 & 1150 & 4.6 & 35.5 & 42.1 & 0.45 & 77.6 \\
\hline MCM-C16/37 & 37 & 2.54 & 1.15 & 1064 & 4.3 & 25.5 & 23.6 & 0.59 & 53.3 \\
\hline MCM-C18/37 & 37 & 3.04 & 1.21 & 1028 & 3.2 & 11.4 & 17.1 & 0.58 & 28.5 \\
\hline MCM-C18/15 & 15 & 2.98 & 0.97 & 1061 & - & 16.5 & 28.1 & 0.75 & 44.6 \\
\hline MCM-C18/37 & 37 & 3.04 & 1.21 & 1028 & 3.2 & 11.4 & 17.1 & 0.58 & 28.5 \\
\hline MCM-C18/60 & 60 & 2.80 & 1.06 & 1019 & - & 2.0 & 20.8 & 0.46 & 22.8 \\
\hline MCM-C18/120 & 120 & 2.82 & 1.12 & 1118 & - & 5.1 & 13.4 & 0.93 & 18.5 \\
\hline MCM-C18/177 & 177 & 3.01 & 0.99 & 1042 & - & 3.1 & 14.8 & 0.87 & 17.9 \\
\hline MCM-C18/370 & 370 & 2.85 & 0.98 & 1044 & - & 2.1 & 14.0 & 0.13 & 16.1 \\
\hline
\end{tabular}

activity, all conversion curves obtained from Al-MCM-41 samples exhibit an exponential decay function, which may be described by the equation:

$X_{t}=X_{o}+k \mathrm{e}^{-\alpha t}$

where $X_{t}$ represents the conversion at a given TOS $=t, X_{o}$ and $k$ are constants, and the exponent $\alpha$ is a parameter accounts for deactivation rate. The results of the fittings are shown in Fig. 1a as solid lines and the corresponding deactivation parameters are depicted in Table 1. The rapid decay in 1,3,5-TiPB conversions (or catalyst activity) indicates that coking is the prominent reason for catalyst deactivation. In general, the catalytic activities of various Al-MCM-41 samples eventually reach plateau at TOS $\geq 4 \mathrm{~h}$ and the conversion level at the same TOS tends to decrease with increasing $\mathrm{Si} / \mathrm{Al}$ ratio (or decreasing $\mathrm{Al}$ content) of the catalyst. It is noted that even for sample with the lowest $\mathrm{Al}$ content $(\mathrm{Si} / \mathrm{Al}=370)$ the initial conversion is still non-zero. Furthermore, that the coke content (obtained at TOS $=6 \mathrm{~h}$ ) also decreases with decreasing $\mathrm{Al}$ content of the Al-MCM-41 samples (Table 1) indicating carbonaceous residues tend to deposit on the acid sites of the catalysts. In an earlier study using solid-state ${ }^{31} \mathrm{P}$ MAS NMR of adsorbed trimethylphosphine oxide (TMPO) as the probe, Zhao et al. [43, 45] reported that two types of acid sites corresponding to ${ }^{31} \mathrm{P}$ chemical shifts of 69 and 63 ppm can be identified in Al-MCM-41. It was found that the observed ${ }^{31} \mathrm{P}$ chemical shifts remain unchanged upon varying $\mathrm{Si} / \mathrm{Al}$ ratios (from 15 to 70 ) indicating that the respective acid strength for each site is invariant with $\mathrm{Al}$ content. The authors also concluded that while the concentration of the stronger acid site (at $69 \mathrm{pm}$ ) decreases with increasing $\mathrm{Si} / \mathrm{Al}$ ratio, the amount of weaker acid site (at $63 \mathrm{ppm}$ ) is invariant with $\mathrm{Al}$ content in the sample. In this context, it may be envisaged that, the carbonaceous residues tend to deposit on active sites during initial TOS $(<4 \mathrm{~h})$ which resulted in a rapid decrease in 1,3,5-TiPB conversion. Similar behaviors were observed for a series of MCM-C18 samples (average pore size ca. $3.0 \mathrm{~nm}$ ) with varied $\mathrm{Si} / \mathrm{Al}$ ratios, as shown in Fig. 1b. The same analysis 
Fig. 1 Variations of 1,3,5-TiPB conversion with time-on-stream during cracking reaction over various MCM-41 samples having different $\mathrm{Si} / \mathrm{Al}$ ratios and with an averaged pore diameter of a 2.6 and $\mathbf{b} 3.0 \mathrm{~nm}$ (Table 1). The solid curves represent results of fittings by Eq. 1 (a)

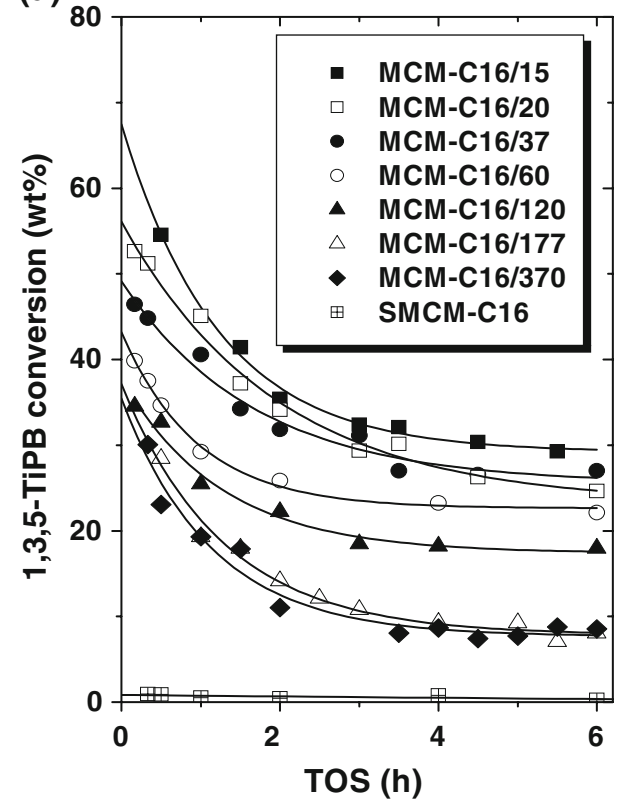

(b)

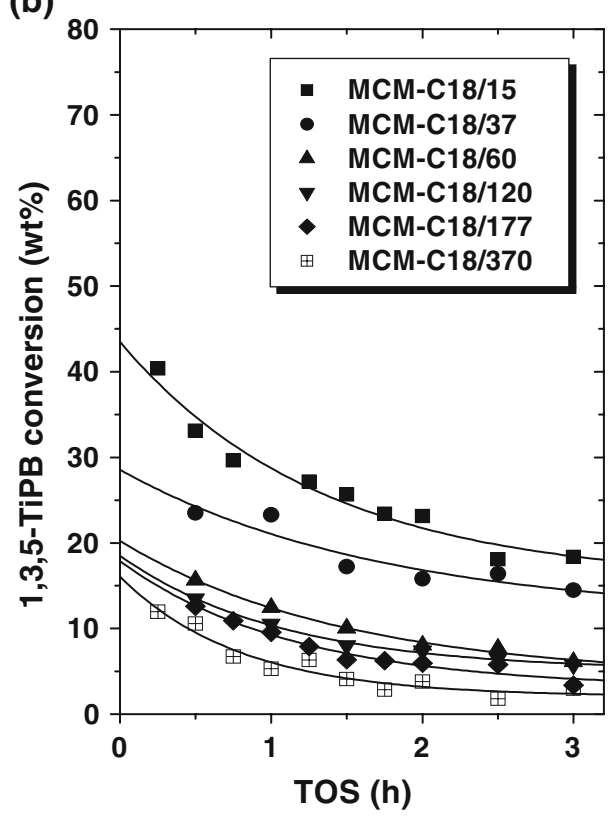

based on Eq. 1 was also performed for this series of sample and reported in Table 1.

To explore the effect of pore size on catalytic performances of Al-MCM-41 during 1,3,5-TiPB cracking, samples with the same $\mathrm{Al}$ content $(\mathrm{Si} / \mathrm{Al}=37)$ but having varied pore diameters (1.57-3.04 nm) were also prepared (Table 1). Figure 2 shows the variations of 1,3,5-TiPB conversions against TOS; the solid curves represent fittings obtained from various samples by Eq. 1 and the related deactivation parameters are also summarized in Table 1 together with their coke contents. It is noted that, both the deactivation rate and coke content remain practically unchanged upon increasing pore size of Al-MCM-41, except for the sample with the smallest pore diameter (MCM-C10/ 37; see Table 1), which exhibits an abnormal high coke content $(9.6 \mathrm{wt} \%)$ and deactivation rate $(\alpha=0.75)$. These observations deserve further discussion (see below).

The catalytic performance of Al-MCM-41 in 1,3,5-TiPB cracking should further be evaluated in terms of product selectivity, by which the molar fraction of major product yields (i.e., $m$-DiPB to cumene ratio) was used as an indicator of de-akylation. It is found that, for Al-MCM-41 catalysts with a fixed pore diameter (viz. $2.6 \mathrm{~nm}$ ), the $m$ $\mathrm{DiPB} /$ cumene ratio remain roughly unchanged with TOS for samples with intermediate range of aluminum content $15 \leq \mathrm{Si} / \mathrm{Al}<60$. Whereas for samples with $\mathrm{Si} / \mathrm{Al} \geq 120$, a sharp increase in $m$-DiPB/cumene ratios at prolonged TOS were also observed. The observed product selectivity in terms of $m$ - to $p$-DiPB ratios fluctuates around the thermodynamic equilibrium compositions of $m$-: $p$-DiPB $=4: 1$. However, this ratio was found slightly higher than the thermodynamic equilibrium value for

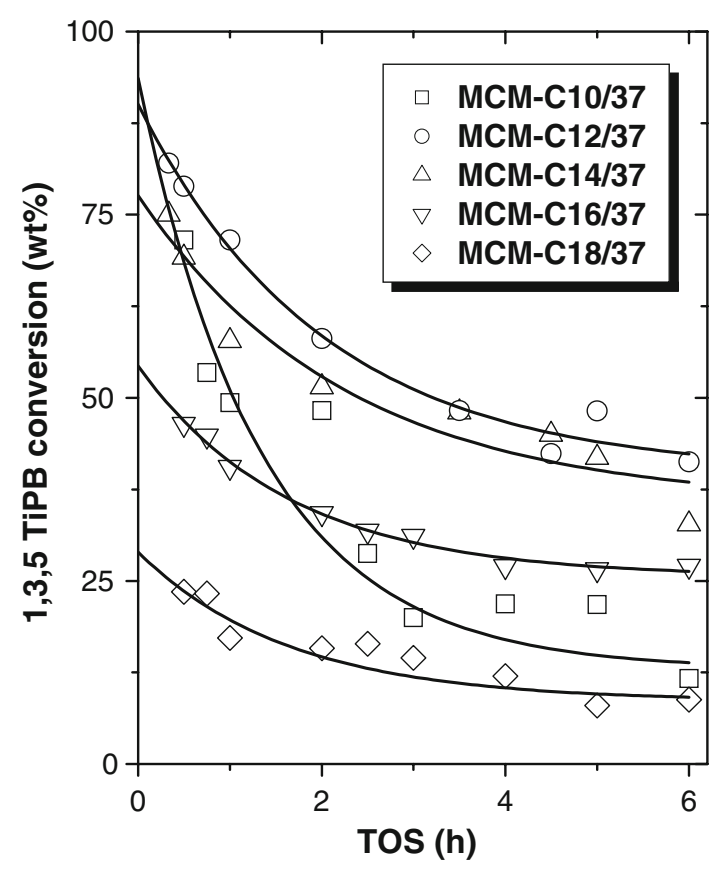

Fig. 2 Variations of 1,3,5-TiPB conversion with time-on-stream during cracking reaction over various Al-MCM-41 samples having different pore diameters but with the same $\mathrm{Al}$ content $(\mathrm{Si} / \mathrm{Al}=37$; Table 1). The solid curves represent results of fittings by Eq. 1

samples with $\mathrm{Si} / \mathrm{Al} \geq 120$. Thus, for $1,3,5$-TiPB cracking over Al-MCM-41 the formation of $p$-DiPB is clearly less favorable for sample with lower $\mathrm{Al}$ content. This is understandable because it is anticipated that para-isomer or cumene can only be obtained in deeper cracking and reconstitution and thus lowering of acidity would disfavor such possibility. 
Figure 3 shows the variations of product selectivity (in terms of $m$-DiPB/cumene molar ratio) against TOS during 1,3,5-TiPB cracking over various Al-MCM-41 samples $(\mathrm{Si} / \mathrm{Al}=37)$ with different pore diameters (Table 1$)$. Selected product distributions during initial TOS $(0.5$ and $2.5 \mathrm{~h}$ ) are also depicted in Table 2. With the exception of the sample MCM-C10/37, which has the smallest pore diameter $(1.57 \mathrm{~nm})$, at a given TOS a steady increase in product selectivity with increasing pore diameter is

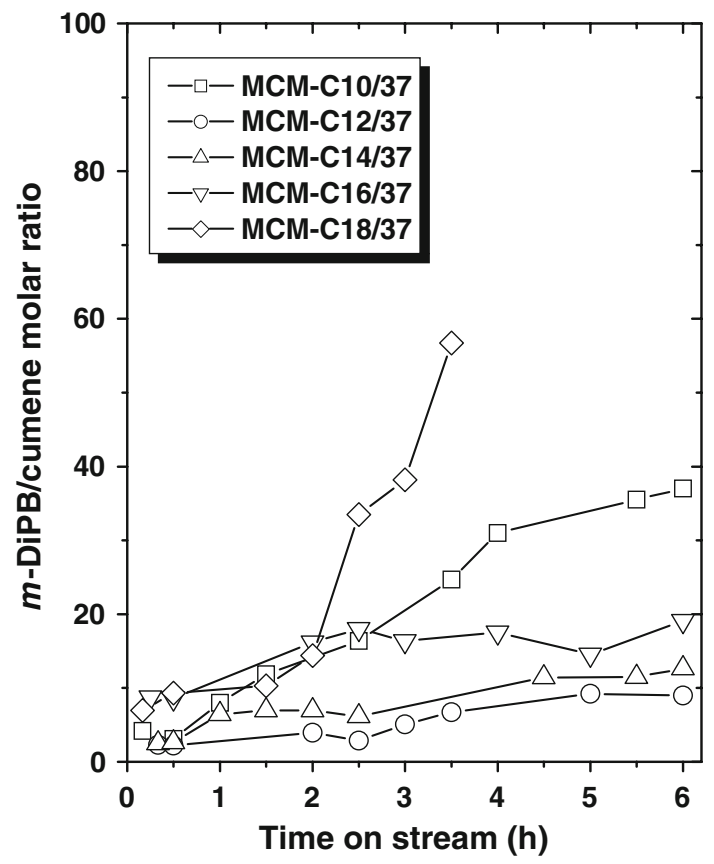

Fig. 3 Variations of product selectivity (in terms of $m$-DiPB/cumene molar ratio) with time-on-stream during 1,3,5-TiPB cracking reaction over various Al-MCM-41 samples having different pore diameters but with the same $\mathrm{Al}$ content $(\mathrm{Si} / \mathrm{Al}=37$; Table 1$)$ evident. In addition, a sharper increase in $m$-DIPB/cumene molar ratio at TOS $\geq 2 \mathrm{~h}$ is observed for sample MCM$\mathrm{C} 18 / 37$, which has the greatest pore diameter of $3.04 \mathrm{~nm}$. Generally speaking, one expects less contact with surface and less cracking (higher $m$-DiPB/cumene molar ratio) activity for larger pore systems.

\subsection{Effect of Al Content and Pore Size on Catalytic Performance of Al-MCM-41}

The initial conversion of $1,3,5$-TiPB (i.e. $X_{o}+k$; see Table 1) is found to decrease rapidly with the $\mathrm{Si} / \mathrm{Al}$ ratio for both series of MCM-C16 and MCM-C18 samples, as shown in Fig. 4a. We found higher conversion for the smaller pore size sample (MCM-16). That the initial conversions eventually reach a respective plateau value of ca. 37 and $18 \mathrm{wt} \%$ for MCM-C16 and MCM-C18 series samples with $\mathrm{Si} / \mathrm{Al} \geq 120$ provide additional support to the notion that hydrocarbon cracking over Al-MCM-41 catalyst requires only weak acidity. Also we note here that presumably an increase in WHSV (or shortening the contact time) should result in a lower 1,3,5-TiPB conversion [44, 46].

For understanding better the data in Fig. 4a, we would like to separate out the $\mathrm{Al}$ effect and the size effect. We choose to re-plot the conversion in terms of an relative $\mathrm{Al}$ concentration, $C_{\mathrm{Al}}=\mathrm{Al} /(\mathrm{Si}+\mathrm{Al})$, to all metallic atoms. Figure $4 \mathrm{~b}$ displays the correlations between the 1,3,5TiPB initial conversion and $\mathrm{Al}$ concentration $\left(C_{\mathrm{Al}}\right)$ for the MCM-C16 and MCM-C18 samples. Both sample series show a linear dependence of 1,3,5-TiPB initial conversions with $\mathrm{Al}$ concentration, as given by the empirical relation:

$X_{i}=\mathrm{P}_{1}+\mathrm{P}_{2} \times C_{\mathrm{Al}}$

Table 2 Product distribution during 1,3,5-TiPB cracking over various Al-MCM-41 samples with different pore diameters ${ }^{\mathrm{a}}$

\begin{tabular}{|c|c|c|c|c|c|c|c|c|c|c|}
\hline \multirow[b]{2}{*}{ TOS (h) } & \multicolumn{2}{|c|}{ MCM-C10/37 } & \multicolumn{2}{|c|}{ MCM-C12/37 } & \multicolumn{2}{|c|}{ MCM-C14/37 } & \multicolumn{2}{|c|}{ MCM-C16/37 } & \multicolumn{2}{|c|}{ MCM-C18/37 } \\
\hline & 0.5 & 2.5 & 0.5 & 2.5 & 0.5 & 2.5 & 0.5 & 2.5 & 0.5 & 2.5 \\
\hline Conversion (wt\%) & 79.6 & 23.7 & 79.9 & 58.1 & 69.1 & 52.8 & 46.4 & 31.8 & 23.5 & 16.4 \\
\hline \multicolumn{11}{|l|}{ Product yield (wt $\%$ ) } \\
\hline Cumene & 13.2 & 0.9 & 16.9 & 10.5 & 11.9 & 4.9 & 3.0 & 1.1 & 1.5 & 0.2 \\
\hline$o$-DiPB & 0.5 & 0.1 & 0.7 & 0 & 0.3 & 0.7 & 0.5 & 0.4 & 0 & 0.1 \\
\hline$m$-DiPB & 47.1 & 19.9 & 50.3 & 41.5 & 42.2 & 38.8 & 35.9 & 25.7 & 19.6 & 13.7 \\
\hline$p$-DiPB & 18.0 & 2.6 & 11.9 & 5.1 & 13.8 & 6.7 & 6.4 & 4.2 & 2.2 & 1.8 \\
\hline 1,3,5-TiPB & 20.4 & 76.3 & 20.1 & 41.9 & 30.9 & 47.2 & 53.6 & 68.2 & 76.5 & 83.6 \\
\hline Others & 0.8 & 0.2 & 0.1 & 1.0 & 0.9 & 1.7 & 0.6 & 0.4 & 0.2 & 0.6 \\
\hline \multicolumn{11}{|c|}{ Product selectively (\%) } \\
\hline Cumene & 16.6 & 3.8 & 21.2 & 18.1 & 17.2 & 9.3 & 6.5 & 3.5 & 6.4 & 1.8 \\
\hline DiPB & 82.4 & 95.4 & 78.7 & 80.2 & 81.5 & 87.5 & 92.2 & 95.3 & 92.8 & 94.5 \\
\hline
\end{tabular}

${ }^{a}$ Reaction condition: $T_{\mathrm{r}}=573 \mathrm{~K} ; \mathrm{WHSV}=15.25 \mathrm{~h}^{-1}$; pressure $=1 \mathrm{~atm} ; \mathrm{N}_{2} / \mathrm{feed}=2.0 \mathrm{~mol} / \mathrm{mol}$ 
Fig. 4 Correlations of 1,3,5TiPB initial conversion with a $\mathrm{Si} / \mathrm{Al}$ ratio and $\mathbf{b} \mathrm{Al}$ concentration for various MCM-C16 and MCM-C18 samples having an averaged pore diameter of 2.6 and $3.0 \mathrm{~nm}$, respectively (Table 1 ). The solid curve represents fitting by an exponential function

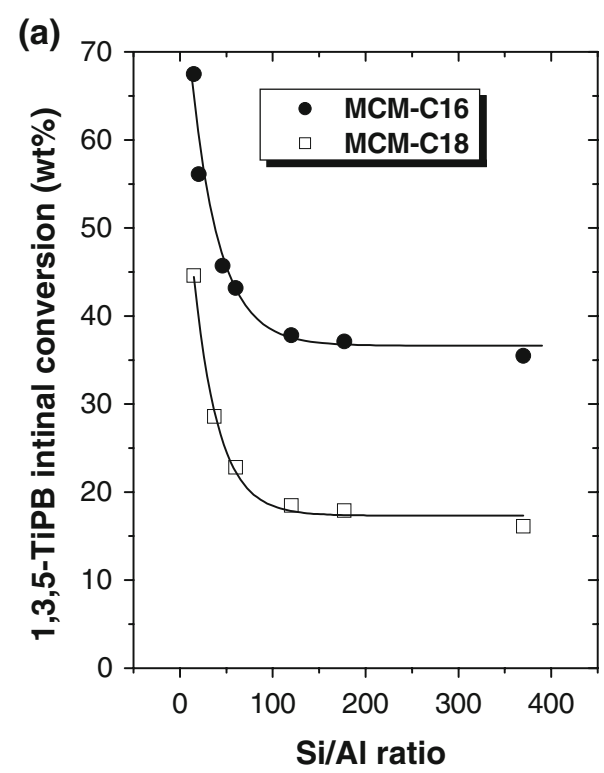

where $X_{i}$ represent 1,3,5-TiPB initial conversions (i.e., the values of $X_{o}+k$ in Table 1), $\mathrm{P}_{1}$ and $\mathrm{P}_{2}$ are constants, and $C_{\mathrm{Al}}=\mathrm{Al} /(\mathrm{Si}+\mathrm{Al})$ denotes $\mathrm{Al}$ concentration in molar fraction. The results of fitting by Eq. 2 are shown in Fig. 4b as solid lines. Accordingly, the values of $\left(\mathrm{P}_{1}, \mathrm{P}_{2}\right)$ obtained from MCM-C16 and MCM-C18 sample series were (34.3, 496.6) and (15.1, 478.2), respectively.

The fact that the two lines in Fig. $4 \mathrm{~b}$ have nearly the same slope $\left(\mathrm{P}_{2}\right)$ indicates that only the intercept values $\left(\mathrm{P}_{1}\right)$ are related to the intrinsic pore size effect. In other words, at a given $\mathrm{Al}$ content, the difference in 1,3,5-TiPB initial conversions between samples with different pore diameters remains constant. The linear increase in 1,3,5-TiPB initial conversions for Al-MCM-41 with increasing $\mathrm{Al}$ content reveals that all acidic sites are well isolated and apparently having the same interaction strength with the reactant. This is in accordance with the conclusions made earlier by Zhao et al. [43, 45] who concluded that, while there are two types of acid sites in Al-MCM-41, the respective acidic strength for each type of acid site remains practically unchanged upon varying $\mathrm{Al}$ content. Thus, for Al-MCM-41 with the same pore diameter, the linear increase in 1,3,5TiPB initial conversions with sample Al content should be associated with the increasing acid sites on the pore walls of the catalysts.

\subsection{Confinement Effect During Cracking Reaction Over Al-MCM-41}

As shown in Fig. 5 and Table 1, a steady decrease in 1,3,5TiPB initial conversions $\left(X_{o}+k\right)$ during cracking reaction over various $\mathrm{Al}-\mathrm{MCM}-41$ samples $(\mathrm{Si} / \mathrm{Al}=37)$ with different diameters are evident, indicating that, for a given $\mathrm{Al}$

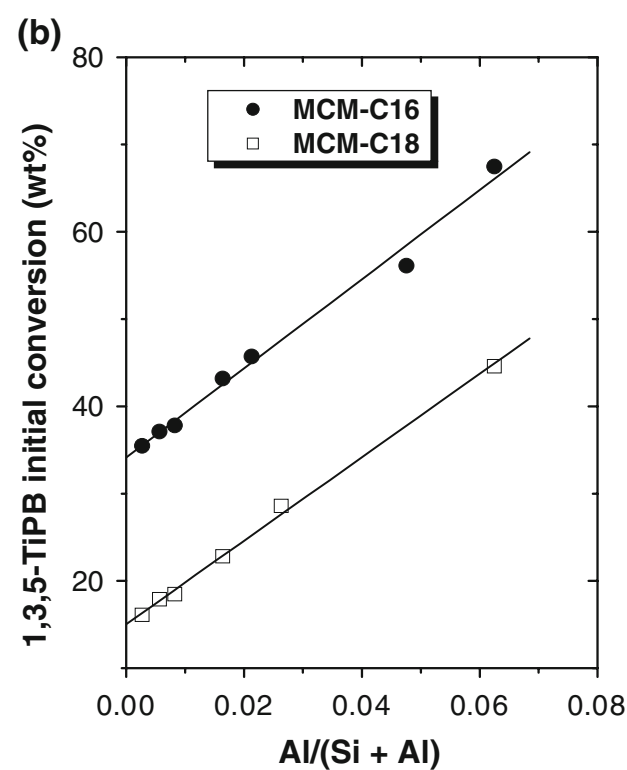

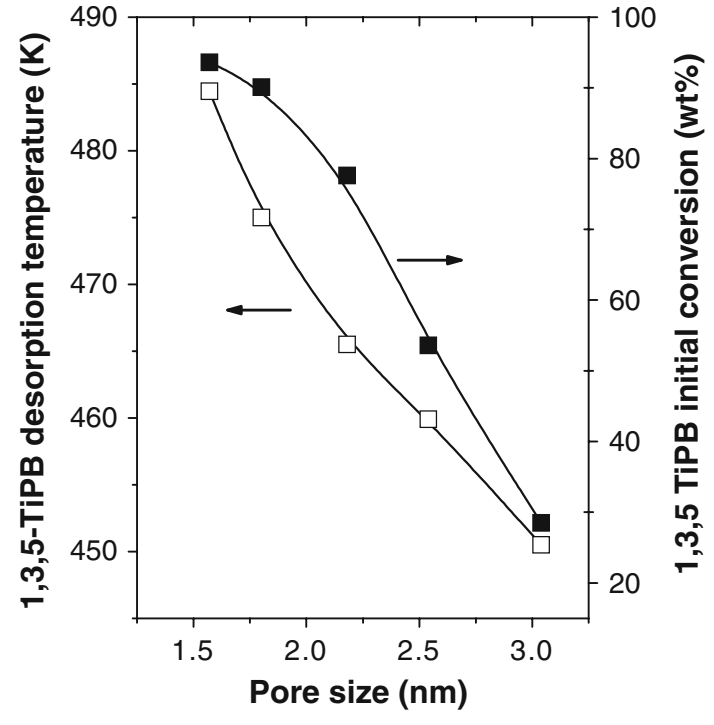

Fig. 5 Correlations of 1,3,5-TiPB initial conversion (right) and desorption temperature (left) with pore diameter for various AlMCM-41samples having the same $\mathrm{Al}$ content $(\mathrm{Si} / \mathrm{Al}=37$; Table 1$)$

content, Al-MCM-41 with smaller pore diameters is more favorable in terms of catalytic activity. Presumably, this phenomenon may be associated with either adsorptive or diffusive properties of the guest/host systems.

To elucidate this point, additional adsorption experiments were performed. Each sample was introduced with saturated amount of 1,3,5-TiPB by vapor transfer under a vacuum apparatus then placed under ambient conditions overnight to ensure a homogeneous adsorbate distribution. Subsequently, each sample was subjected to desorption test by thermogravimetric analysis (TGA) under the same conditions: ca. $10 \mathrm{mg}$ of 1,3,5-TiPB loaded sample was 
heated to $1,173 \mathrm{~K}$ at a rate of $5 \mathrm{~K} / \mathrm{min}$ under dried $\mathrm{N}_{2}$. Typically, the desorption curves obtained from such guest/ host systems reveal a main desorption peak at a temperature proximity to the boiling point of bulk 1,3,5-TiPB $(507 \mathrm{~K})$ together with a lower intensity tail spanning toward higher temperatures (not shown). It is anticipated that the low-temperature desorption peak should be associated with pore-filling effect in confined nanopores, whereas the high-temperature tail should be related to adsorption-desorption. Accordingly, the temperatures at which 1,3,5-TiPB completely desorbs from various Al-MCM-41 samples were recorded and the results are depicted in Fig. 5. The variations of 1,3,5-TiPB desorption temperature with pore diameter of Al-MCM-41 follow a trend similar to the observed 1,3,5-TiPB initial conversions. Thus, it is concluded that, for catalysts with a constant $\mathrm{Al}$ content, the higher initial conversion observed in Al-MCM-41 catalyst with a smaller pore diameter in 1,3,5-TiPB cracking may be associated with the higher adsorption strength rendered by the guest/host system. The smaller pore system apparently is a stronger absorbent for 1,3,5-TiPB. This observation is in line with the results obtained from recent calorimetric experiments of hydrocarbon adsorption on mesoporous aluminosilicates [29, 30]. Jänchen et al. [29] measured heat of adsorption of several probes. They found whereas the heats of adsorption of acetonitrile are mainly influenced by a specific interaction on acidic sites in molecular sieves, the adsorption heat of non-polar substance is determined by pore size; the smaller the pore size the higher the heat of adsorption. On the other hand, Meziani et al. [30] found that incorporation of $\mathrm{Al}$ into the MCM-41 silica matrix markedly enhances its acidic character, which in turn increases the interaction of hydrocarbon with the surface. Here, we identify the catalytic cracking activities of Al-MCM-41 with increased hydrocarbon adsorption ability of the surface which goes with higher $\mathrm{Al}$ content and smaller pore size.

At this point, we can give a schematic picture of the "pure" curvature effect on the adsorption and cracking behavior of 1,3,5-TiPB in MCM-41. It has been shown there are two (and only two) factors in determining the cracking activity, pore size and $\mathrm{Al}$ content. The parallel lines in Fig. 4b can be understood as the two factors are independent. The $\mathrm{Al}$ induced acid sites are probably isolated enough so that their catalytic activities are simple additive. The "pure" curvature effect in catalytic activity is found to exist in the initial activity where secondary effects such as coking are not yet operative. We then found this "pure" curvature effect is simply correlated with the interaction strength, as measured by desorption temperature, of the surface. Figure 6 provides one a schematic picture of the adsorptive interaction of a hypothetical molecule (size $\sim 0.85 \mathrm{~nm}$ ) interacting with a pore of size

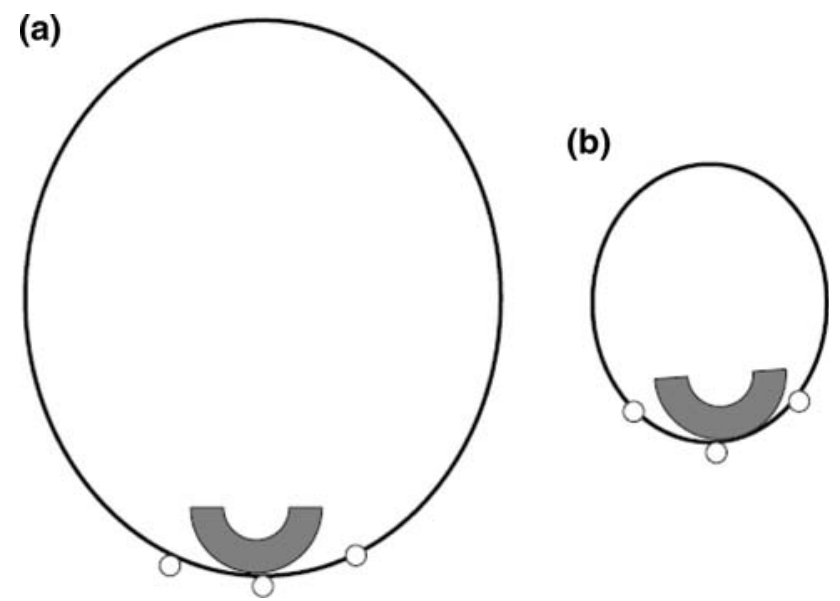

Fig. 6 Schematic diagram depicting a molecule (size $\sim 0.85 \mathrm{~nm}$ ) interacting adsorptively with a silica pore size of $\mathbf{a} 3.6 \mathrm{~nm}$ and $\mathbf{b}$ $1.8 \mathrm{~nm}$ (see text)

of 3.6 and $1.8 \mathrm{~nm}$, respectively. The small circle on the surface of pore represents acid sites which gives additional interaction strength. Assuming uniform distribution of $\mathrm{Al}$, the interaction of the hypothetical molecule should be stronger in the case of smaller pore because of a stronger attractive strength. In the case of higher $\mathrm{Al}$ content, this stronger interaction would lead to longer residence time on surface and thus to stronger cracking. It is noteworthy that Fig. 6 only provides one plausible explanation and that other possibilities, such as a non-uniform distribution of surface acid sites, may exist. However, these would require further ad hoc assumptions.

The anomalous behavior observed for the MCM-C10/37 sample in terms of its catalytic performance during 1,3,5 TiPB cracking reaction deserves further discussions. In view of the observed high coke content and deactivation rate compared with other Al-MCM-41 with the same $\mathrm{Si} / \mathrm{Al}=37$, it is apparent that the MCM-C10/37 sample, being having a pore size $(1.57 \mathrm{~nm}$, see Table 1$)$ closest to the kinetic diameter of the reactant 1,3,5-TiPB (ca. $0.85 \mathrm{~nm}$ ), is more vulnerable to deactivation by coking. The abnormal behavior observed in 1,3,5-TiPB conversion (Fig. 2) and product selectivity (Fig. 3) for MCM-C10/37 can thus be attributed to diffusion limitations caused by deposition of carbonaceous residues within the intra-particle voids of the catalyst during reaction. Obviously, such diffusion hindrance induced by coking is more severe for catalyst having a smaller pore aperture. The high adsorption strength for 1,3,5-TiPB (Fig. 5) and progressive porenarrowing by coking upon increasing TOS thus effectively prohibit secondary reactions to occur in the pores of MCMC10/37 sample. On the other hand, samples with greater pore size should allow faster diffusion for reactant and product molecules within the pores of the catalyst. This is in line with the observed decrease in both initial conversion 
and adsorption strength of 1,3,5-TiPB with increasing pore diameter of Al-MCM-41 in Fig. 5. That the total coke content and deactivation rate are invariant with pore size (Table 1) provides further supports to the above argument.

Regardless of the afore discussions of catalytic performances based on initial conversion of 1,3,5-TiPB cracking over various Al-MCM-41 catalysts, during which molecular catalytic activities are mainly dictated by thermodynamic effects (adsorption energy) and less influenced by kinetic effects (diffusion and coking) [18, 19]. As such, a consistent decrease in 1,3,5-TiPB initial conversion with pore size of Al-MCM-41 samples was observed, as shown in Fig. 5. For kinetic effect, an alternative evaluation of activity at extended time-on-stream is used. Figure 7 displays variations of 1,3,5-TiPB conversion with pore size of Al-MCM-41 $(\mathrm{Si} / \mathrm{Al}=37)$ at $\mathrm{TOS}=6 \mathrm{~h}($ see Fig. 2) and at steady state (TOS $\rightarrow \infty$; i.e., the $X_{o}$ values listed in Table 1). In both cases, nearly overlapping volcano curves were observed in which catalytic activity increases with decreasing pore diameter to a maximum $\left(\mathrm{d}_{\text {max }}\right.$; at ca. $\left.1.8 \mathrm{~nm}\right)$ and then decreases. The occurrence of such 'volcano curve' is also found in other confined catalysis systems, for examples, cyclohexanone acetalization over Al-MCM41 ( $\left.\mathrm{Si} / \mathrm{Al}=400 ; \mathrm{d}_{\max } \sim 1.9 \mathrm{~nm}\right)$ [23], 1-hexene isomerization over Al-MCM-41 ( $\mathrm{Si} / \mathrm{Al}=400$; $\mathrm{d}_{\max } \sim 4.0 \mathrm{~nm}$ ) [24], methanol oxidation over V-MCM41 (V loading ca. $0.35 \mathrm{wt} \% ; \mathrm{d}_{\max } \sim 2.2 \mathrm{~nm}$ ) [25],

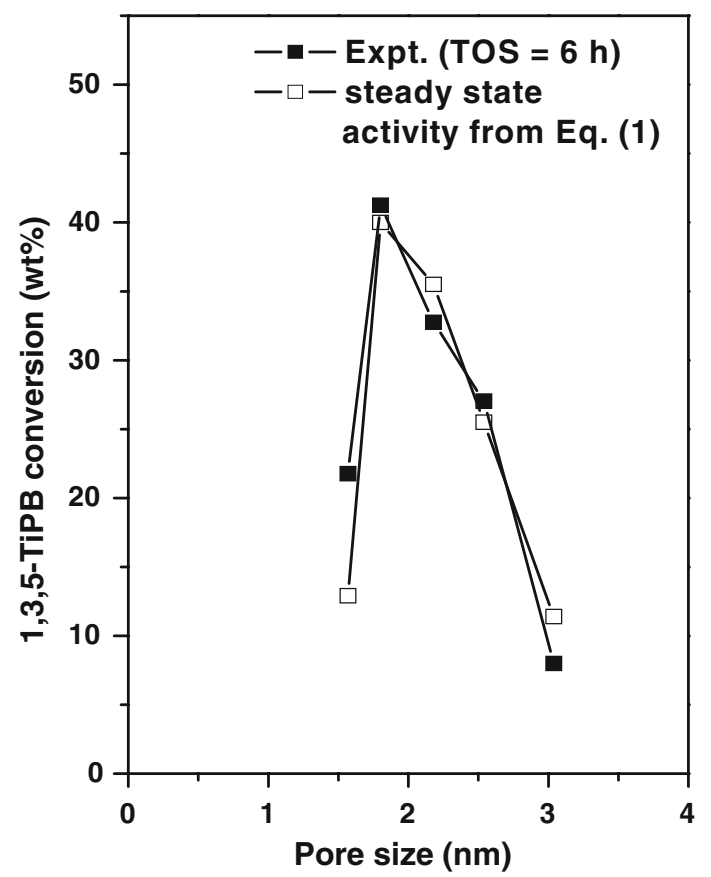

Fig. 7 Correlations of 1,3,5-TiPB final conversion with pore diameter of Al-MCM-41 with $\mathrm{Si} / \mathrm{Al}=37$. Results obtained from experimental data at TOS $=6 \mathrm{~h}(\boldsymbol{\square})$ and fitted $X_{o}$ values $(\square$; see Table 1) based on Eq. 1 are both shown nitroaldol condensation catalyzed by $\mathrm{NH}_{2}$-functionalized mesoporous silica spheres ( $\mathrm{N}$ content ca. $2 \mathrm{mmol} / \mathrm{g}$; $\left.\mathrm{d}_{\max } \sim 1.5 \mathrm{~nm}\right)$ [26], Fischer-Tropsch $\left(\mathrm{C}_{5+}\right)$ synthesis catalyzed by Co-supported mesoporous silica (Co contents ca. 5-7 wt \% $\mathrm{d}_{\max } \sim 5.0 \mathrm{~nm}$ ) [27], and 1-hexene hydrogenation catalyzed by $\mathrm{Rh}$-complex tethered MCM-41 silica $\left(\mathrm{d}_{\max } \sim 5.0 \mathrm{~nm}\right)$ [28]. A possible explanation of the occurrence of such pore size optimum in the guest/host systems is that bulkier molecules tend to be more diffusionlimited for the smallest pore size catalyst. They tend to encounter more frequently with acidic site and undergo deeper cracking and coking. On the other hand at larger pore size end in Fig. 6, the coking is much less severe then the conversion is more determined by adsorption effect, following the same trend as initial activity (Fig. 5); i.e., decreasing conversion upon increasing pore size.

Finally we note that, for the system of $1,3,5$-TiPB cracking over Al-MCM-41 studied herein, a similar linear dependence in initial conversion with $\mathrm{Al}$ content was observed for catalysts having different pore size (Fig. 4b), revealing that acidic sites are well isolated and have similar catalytic activity in these systems. This is also supported by the similar deactivation rate $(\alpha \sim 0.53 \pm 0.05)$ and coke content (3-5 wt\%) observed for Al-MCM-41 with pore sizes ranging from 1.8 to $3.0 \mathrm{~nm}$ (see Fig. 2 and Table 1), except for MCM-C10/37 (pore size $1.57 \mathrm{~nm}$ ); which exhibits an abnormal high coke content (9.6 wt \%) and deactivation rate $(\alpha=0.75)$. For pores smaller than $1.8 \mathrm{~nm}$, coking becomes severe and the reaction rate may be influenced by a complex interplay of diffusion, local concentration, and adsorption properties and its surface curvature effect.

\section{Conclusions}

The catalytic performances of mesoporous Al-MCM-41 molecular sieves during cracking reaction have been studied. Al-MCM-41 catalysts with different Al contents and pore sizes were synthesized and their catalytic activities examined using 1,3,5-TiPB cracking as the test reaction. The activity of the catalyst was found to decrease exponentially with time-on-stream; coking was found responsible for catalyst deactivation. The total coke content and deactivation rate are found to depend mostly on $\mathrm{Al}$ content of the catalysts rather than their pore diameters unless it is very small. We found an intrinsic pore size effect by carefully controlling the $\mathrm{Al}$ content to the same relative concentration. For Al-MCM-41 with the same Al content, both the initial activity and adsorption strength of 1,3,5-TiPB are found to increase with decreasing pore size of the catalysts indicating that adsorption rather than diffusion is the controlling effect for the catalytic performance 
of Al-MCM-41 during cracking reaction. On the other hand, for long time limit (steady state) regime, the conversion shows a distinct volcano curve as pore size is increased indicating severe coking for the smallest pore.

In terms of product selectivity, while the ratio of $m-/ p$ DiPB isomers maintained at a level close to the thermal equivalent compositions for most of the samples, a steady increase in DiPB isomers/cumene product ratio with increasing pore diameter indicates that secondary reactions are more likely to occur in catalyst with smaller pore size. On the other hand, for Al-MCM-41 with the same pore diameter, a linear increase in 1,3,5-TiPB initial conversions with increasing $\mathrm{Al}$ content was observed. In terms of their selectivity, while the $m$-DiPB/cumene ratio remain practically unchanged with TOS for samples with $15<\mathrm{Si}$ / $\mathrm{Al}<60$, a sharp increase in the corresponding product ratios with $\mathrm{TOS}$ were observed for $\mathrm{Si} / \mathrm{Al} \geq 120$. This together with the fact that the $m-/ p$-DiPB ratios deviate from thermal equilibrium compositions revealing that, for 1,3,5-TiPB cracking over Al-MCM-41 with fixed pore diameter and WHSV, formation of $m$-DiPB is more favorable for sample with lower Al content. It is concluded that cracking reaction, which requires only weak acidity, is mainly controlled by the dispersion of acid sites and should be more favorable for Al-MCM-41 catalyst with a smaller pore diameter and a greater $\mathrm{Al}$ concentrations.

We have demonstrated the important pore size and $\mathrm{Al}$ content effects in employing MCM-41 as a "nano-reactor", in this study. The catalytic activities mainly depend on the capacity of adsorption of reactant, which can be finely controlled by pore size/wall engineering. This study elucidated that mesoporous materials with controllable pores indeed provide the means and opportunities to study more complex catalytic reactions.

Acknowledgments The authors thank Professors Soofin Cheng and Ben-Zu Wan for helpful discussions. The financial supports of this research by the National Science Council, Taiwan (NSC95-2113-M001-040-MY3 and NSC-94-2752-M-002-004-PAE) are also gratefully acknowledged.

\section{References}

1. Kresge CT, Leonowicz ME, Roth WJ, Vartuli JC, Beck JS (1992) Nature 359:710

2. Beck JS, Vartuli JC, Roth WJ, Leonowicz ME, Kresge CT, Schmitt KD, Chu CT-W, Olson DH, Sheppard EW, McGullen SB, Higgins JB, Schlenker JL (1992) J Am Chem Soc 114:10834

3. Selvam P, Bhatia SK, Sonwane CG (2001) Ind Eng Chem Res 40:3237

4. Widenmeyer M, Anwander R (2002) Chem Mater 14:1827

5. Mou CY, Lin HP (2000) Pure Appl Chem 72:137

6. Lin HP, Mou CY (2002) Acc Chem Res 35:927

7. Lin HP, Yang LY, Mou CY, Liu SB, Lee HK (2000) New J Chem $24: 253$
8. Liu YH, Lin HP, Mou CY (2004) Langmuir 20:3231

9. Dabrowski A (2001) Adv Colloid Interface Sci 93:135

10. Stein A (2003) Adv Mater 15:763

11. Corma A (1997) Chem Rev 97:2373

12. Ciesla U, Ferdi S (1999) Microporous Mesoporous Mater 27:131

13. Rozwadowski M, Lezanska M, Wloch J, Erdmann K, Golembiewski R, Kornatowski J (2001) Langmuir 17:2112

14. Gelb LD, Gubbins KE, Radhakrishnan R, Sliwinska-Bartkowiak M (1999) Rep Prog Theo Phys 62:1573

15. Chen WH, Zhao Q, Lin HP, Yang YS, Mou CY, Liu SB (2003) Microporous Mesoporous Mater 66:209

16. Klafter J, Drake JM (1989) Molecular Dynamics in Restricted Geometries. John Wiley \& Sons, Inc., New York

17. Trens P, Tanchoux N, Galarneau A, Fajula F (2005) J Phys Chem B 109:16415

18. Santiso EE, George AM, Turner CH, Kostov MK, Gubbins KE, Nardelli MB, Sliwinska-Bartkowiak M (2005) Appl Surf Sci 252:766

19. Santiso EE, Kostov MK, George AM, Nardelli MB, Gubbins KE (2007) Appl Surf Sci 253:5570

20. Konishi Y, Okazaki M, Toriyama K, Kasai T (2001) J Phys Chem B 105:9101

21. Wei D, Cheuh WT, Haller GL (1999) Catal Today 51:501

22. Hu XC, Foo ML, Chuah GK, Jaenicke S (2000) J Catal 195:412

23. Iwamoto M, Tanaka Y, Sawamura N, Namba S (2003) J Am Chem Soc 125:13032

24. Pariente S, Trens P, Fajula F, Di Renzo F, Tanchoux N (2006) Appl Catal A 307:51

25. Yang YH, Du G, Lim SY, Haller GL (2005) J Catal 234:318

26. Suzuki TM, Tamamoto M, Fukumoto K, Akimoto Y, Yano K (2007) J Catal 251:249

27. Khodakov AY, Griboval-Constant A, Bechara R, Zholobenko VL (2002) J Catal 206:230

28. Goettmann F, Sanchez C (2007) J Mater Chem 17:24

29. Jänchen J, Stach H, Busio M, van Wolput JHMC (1998) Thermochim Acta 312:33

30. Meziani MJ, Zajac J, Douillard J-M, Jones DJ, Partyka S, Rozière J (2001) J Colloid Interface Sci 233:219

31. Trens P, Tanchoux N, Maldonado D, Galarneau A, Di Renzo F, Fajula F (2004) New J Chem 28:874

32. On DT, Desplantier-Giscard D, Danumah C, Kaliaguine S (2001) Appl Catal A 222:299

33. Sayari A (1996) Chem Mater 8:1840

34. Taguchi A, Schüth F (2005) Microporous Mesoporous Mater 77:1

35. Reddy KM, Song C (1996) Catal Lett 36:103

36. Zhai SR, Zhang Y, Wu D, Sun YH, Wang SJ (2006) Topics Catal 39:227

37. Koch H, Reschetilowski W (1998) Microporous Mesoporous Mater 25:127

38. Ghanbari-Siahkali A, Philippou A, Dwyer J, Anderson MW (2000) Appl Catal A 192:57

39. Lin HP, Mou CY (1996) Science 273:765

40. Lin HP, Cheng S, Mou CY (1996) Microporous Mater 10:111

41. Lin HP, Cheng S, Mou CY (1998) Chem Mater 10:581

42. Lin HP, Wong ST, Mou CY, Tang CY (2000) J Phys Chem B 104:8967

43. Zhao Q, Chen WH, Huang SJ, Wu YC, Lee HK, Liu SB (2002) Stud Surf Sci Catal 141:453

44. Chen WH, Jong SJ, Pradhan A, Lee TY, Wang I, Tsai TC, Liu SB (1996) J Chin Chem Soc 43:305

45. Zhao Q, Chen WH, Huang SJ, Wu YC, Lee HK, Liu SB (2002) J Phys Chem 106:4462

46. Chen WH, Tsai TC, Jong SJ, Zhao Q, Tsai CT, Wang I, Lee HK, Liu SB (2002) J Mol Catal A 181:41 